\title{
Respostas morfoanatômicas de Bowdichia virgilioides (Fabaceae) à deriva de glifosato em agroecossistema do cerrado brasileiro
}

Este estudo avaliou as respostas morfoanatômicas de Bowdichia virgilioides (Fabaceae) sob deriva de glifosato em um agroecossistema do Cerrado brasileiro. Duas coletas de folhas foram realizadas para dez indivíduos de duas áreas: área de borda (AB) e área controle (AC). Os sintomas visuais foram avaliados com índices de injúria foliar (IIF) e de severidade (IS), os anatômicos através da utilização de técnicas usuais de anatomia e os micromorfométricos por meio do software Anat Quanti. Cloroses e necroses foram encontradas. Os IIFs e ISs foram maiores para as folhas da AB e pode ser devido aos impactos que ocorrem na borda de manejo da área agrícola. Cloroplastos arredondados, plasmólise celular, hiperplasia, proliferação e colapso celular, sintomas similares aos encontrados em estudos de simulação de deriva de glifosato, foram notados. A espessura do parênquima paliçádico e, consequentemente, do mesofilo diferiram significativamente entre coletas, na $A B$, e entre os indivíduos da $A C$ e da $A B$, na coleta de maio de 2017. Fatores como a maior incidência solar nas plantas de $A B$, provável ocorrência de outras pulverizações, assim como maior período de exposição e ação de contaminantes nas folhas da segunda coleta explicam essas alterações. Em campo, as avaliações visual, anatômica e morfométricas dos sintomas foliares foram sugestivas de deriva de agrotóxicos.

\section{Morphoanatomical responses of Bowdichia virgilioides (Fabaceae) to glyphosate drift in Brazilian cerrado agroecosystem}

\begin{abstract}
This study evaluated the morphoanatomical responses of Bowdichia virgilioides (Fabaceae) under glyphosate drift in an agroecosystem in the Brazilian Cerrado. Two leaf collections were carried out for ten individuals from two areas: border area (BA) and control area (CA). Visual symptoms were evaluated with leaf injury (LII) and severity (SI) indices, the anatomical through the use of usual anatomy techniques and the micromorphometric through the Anati Quanti software. Chlorosis and necrosis were found. The IIFs and ISs were higher for BA leaves and may be due to impacts that occur at the management edge of the agricultural area. Rounded chloroplasts, cell plasmolysis, hyperplasia, cell proliferation and collapse, symptoms similar to those found in glyphosate drift simulation studies, were noted. The thicknesses of the palisade parenchyma and, consequently, of the mesophyll differed significantly between collections, in BA, and between individuals in CA and BA, in the May 2017 collection. Factors such as higher solar incidence in plants of BA, probable occurrence of other sprays, as well as a longer period of exposure and the action of contaminants on the leaves of the second collection explain these changes. In the field, visual, anatomical and morphometric evaluations of leaf symptoms were suggestive of pesticide drift.
\end{abstract}

Keywords: Bioindicator; Biomonitoring; Non-target plant; Symptoms morphoanatomical.

Topic: Botânica Agrícola

Reviewed anonymously in the process of blind peer.
Received: 03/07/2021

Approved: 28/07/2021
Esmeralda Pereira de Araújo

Universidade de Brasília, Brasil

http://lattes.cnpq.br/9142370169099596

http://orcid.org/0000-0002-8591-894X

esmeraldaneta.a@gmail.com

Kellen Lagares Ferreira Silva

Universidade Federal do Tocantins, Brasil

http://lattes.cnpq.br/9200174067176129

http://orcid.org/0000-0002-1810-4540

lagares@mail.uft.edu.br
Referencing this:

ARAÚJO, E. P.; SILVA, K. L. F.. Respostas morfoanatômicas de Bowdichia virgilioides (Fabaceae) à deriva de glifosato em agroecossistema do cerrado brasileiro. Revista Ibero Americana de Ciências Ambientais, v.12, n.7, p.112-124, 2021. DOI: http://doi.org/10.6008/CBPC2179-6858.2021.007.0011 


\section{INTRODUÇÃO}

A compreensão dos impactos de pesticidas à biodiversidade dos agroecossistemas ainda é escassa. Entretanto, estudo realizado em 8 países europeus demonstrou que fazendas com intensificação agrícola, e que faziam uso de fungicidas e inseticidas, apresentaram efeitos negativos à biodiversidade circundante (GEIGER et al., 2010). Um caminho pelo qual é possível pesticidas atingirem áreas circundantes é a ocorrência de deriva (ZHANG et al., 2018; BUENO et al., 2017; CUNHA, 2008). Na deriva as partículas dos pesticidas aplicados à cultura se perdem para o ambiente (CUNHA, 2008) e alcançam áreas não visadas, como a vegetação nativa. Dependendo das condições meteorológicas, se estende por vários quilômetros (LUCADAMO et al., 2018). Pode ser dividida em endoderiva, perdas dentro da área pulverizada, e exoderiva, perdas para áreas de entorno (SOUZA et al., 2011).

No Brasil os usos de pesticidas ocorrem em áreas agrícolas de diferentes domínios, dentre eles o Cerrado. Essa é a maior, mais rica, e muito possivelmente, a mais ameaçada savana do mundo (SILVA et al., 2002) e é considerada um dos mais importantes hotspots de biodiversidade do planeta (MYERS et al., 2000). No sul do Cerrado, a fronteira mais antiga, a cultura predominante é a soja; na região de Mato Grosso existem diferentes pressões devido o estado também fazer parte da Amazônia Legal; e na parte central ocorre o MATOPIBA, acrônimo dos estados Maranhão, Tocantins, Piauí e Bahia, região com forte expansão da soja na última década (RAUSCH et al., 2019) e considerada como a última fronteira agrícola brasileira (SPERA et al., 2016). O avanço das fronteiras agrícolas causa tensões ao Cerrado e às comunidades humanas que vivem neste domínio (SOUZA et al., 2018).

O agroecossistema brasileiro é composto por, dentre outras, Áreas de Preservação Permanente, Reserva Legal e de uso alternativo do solo, como a agricultura (BRASIL, 2012). 0 agrotóxico mais utilizado nas lavouras brasileiras é o glifosato (IBAMA, 2020). Seu grande uso é devido seu amplo espectro de cobertura (SCHRÜBBERS et al., 2014), e no Cerrado, também pela forte produção de soja na região (SPERA et al., 2016). É usado no Brasil desde 1978 (GALLI et al., 2005) e sua deriva é preocupante por ele não ter seletividade, ser altamente ativo em espécies de plantas sensíveis a pequenas doses e por sua aplicação ocorrer várias vezes ao ano, no pré e pós-emergente, por vias aérea ou terrestre (REDDY et al., 2010).

Com impactos iminentes de agrotóxicos à vegetação, o uso de espécies bioindicadoras para avaliar diferentes danos à biota tem se tornado uma alternativa de biomonitoramento. O biomonitoramento consiste em obter respostas das plantas às mudanças no ambiente e acompanhar sua evolução ao longo do tempo (TEMMERMAN et al., 2004). Ao serem expostas, plantas podem apresentar, por exemplo, sintomas fisiológicos, morfoanatômicos e visíveis que são usados como biomarcadores aos danos provocados pelos agrotóxicos. No Cerrado, estudos em ambiente controlados já foram conduzidos para avaliar espécies nativas como bioindicadoras, identificando seus biomarcadores para deriva de glifosato em: Kielmeyera lathrophyton Saddi (Calophyllaceae), Solanum lycocarpum A.St.-Hil (Solanaceae) e Bowdichia virgilioides Kunth (Fabaceae) (MACHADO et al., 2013), Caryocar brasiliense Camb. (SILVA et al., 2016), Alibertia edulis Rich. (Rubiaceae) e Pouteria torta Mart. (Sapotaceae) (SILVA et al., 2019), Handroanthus chrysotrichus (Mart. 
Ex DC) Mattos (Bignoniaceae) e Garcinia gardneriana (Planch. \& Triana) Zappi (Clusiaceae) (SILVA et al., 2020).

Em simulação de deriva, evidências sobre impactos da deriva do herbicida glifosato às plantas nativas do Cerrado foram constatadas. Dentre elas, evidências como cloroses, necroses, redução da epiderme e do parênquima para B. virgilioides (MACHADO et al., 2013; OLIVEIRA et al., 2021), espécie brevidecídua, com queda foliar ocorrente, geralmente, de junho a setembro (PIRANI et al., 2009) e com alta distribuição no Cerrado brasileiro (ALBUQUERQUE et al., 2007). Porém, estudos em condições reais, em campo, podem demonstrar potenciais respostas dessas plantas (EGAN et al., 2014) e confirmar respostas visualizadas na simulação de deriva. Respostas das plantas nativas em condições de campo ainda não foram avaliadas no Cerrado. Dessa forma B. virgilioides foi usada como bioindicadora para avaliar suas respostas morfoanatômicas para deriva de glifosato em um agroecossistema do Cerrado brasileiro.

\section{MATERIAIS E MÉTODOS}

\section{Histórico da área de estudo, condições microclimáticas e ambientais}

O estudo foi realizado em um agroecossistema composto por lavoura e áreas de preservação permanente e reserva legal no Cerrado do estado do Tocantins (Figura 1a). Duas áreas foram delimitadas para a seleção de indivíduos e coletas de suas folhas: área controle $(A C)$ e área de borda (AB). A AC foi delimitada dentro da Reserva Legal da fazenda 2, por ser mais afastada da área de lavoura. A AB foi delimitada na borda da vegetação nativa, cerca de até $5 \mathrm{~m}$ para o seu interior, que é a região do entorno da área de manejo agrícola da fazenda 1 (Figura 1a).

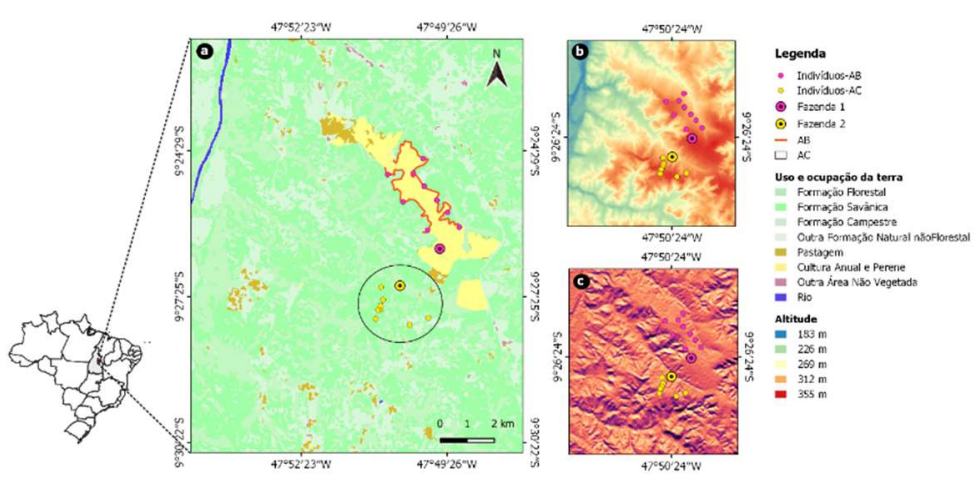

Figura 1: a) localização e uso e ocupação da terra das áreas de estudo; b) altitude da área e c) relevo sombreado evidenciando as regiões mais altas, divisores de águas, e os locais em que os indivíduos ocorrem. Fonte: MapBiomas (2018) e INPE (2008).

A área agrícola, localizada na fazenda 1, é manejada há 17 anos com as monoculturas de soja, sorgo, milho e feijão, e faz uso do sistema de plantio direto na palha. A rotatividade da lavoura é constante, por isso sempre há monocultura plantada. $\mathrm{O}$ uso de herbicidas para eliminação de plantas daninhas ocorre duas vezes ao ano: no pré e pós emergente. Os herbicidas mais usados são o glifosato (Roundup Transbord), para o pósemergente, e Spider ${ }^{\circ}$ R 840 WG quando necessário no pré-emergente. Na calda a ser pulverizada é adicionado adjuvante e, quando existe necessidade, os dois herbicidas são usados.

As áreas de estudo estão localizadas na parte superior do relevo, sendo, principalmente a $A B$, 
próxima às áreas com quebras de relevo, ou seja, divisores de água (Figuras 1b-c). Em novembro de 2016 a variação da temperatura na região foi de $18,1^{\circ} \mathrm{C}$ a $39,7^{\circ} \mathrm{C}$, a velocidade do vento oscilou de 0,2 a $6,4 \mathrm{~m} / \mathrm{s}$, a direção do vento alternou de $1^{\circ}$ a $359^{\circ}$, a precipitação acumulada foi de $79,2 \mathrm{~mm}$ e a umidade do ar variou de 32 a 98\% na estação pluviométrica de Rio Sono (INMET, 2016). Em maio de 2017 a temperatura variou de $18,1^{\circ} \mathrm{C}$ a $35,7^{\circ} \mathrm{C}$, a precipitação acumulada foi de $2 \mathrm{~mm}$ e a umidade do ar oscilou de 32 a $98 \%$ (INMET, 2017). Para maio não foram encontrados registros das variáveis de velocidade e direção do vento nesta estação pluviométrica.

\section{Coletas das folhas de B. virgilioides}

Dez indivíduos foram definidos e marcados com tecido amarelo e placas, com numerações para cada área. As coletas das folhas ocorreram de forma aleatória e com uso de podão (Figure 2c). Duas coletas de folhas foram realizadas, sendo a primeira em novembro de 2016, depois da aplicação de $3.5 \mathrm{~L}$ do herbicida glifosato com adição de $0.35 \mathrm{~g}$ do herbicida Spider e adjuvante, durante a cultura da soja, e a segunda em maio de 2017, durante a cultura do sorgo. Também se suspeita que outras pulverizações tenham acontecido deste intervalo até a realização da segunda coleta. A pulverização na área é realizada por meio terrestre, com uso de pulverizador Columbria 3000, do tipo jato cônico vazio, com 14 bicos, sendo o volume da calda de 100 $\mathrm{L} \mathrm{ha}^{-1}$ (Figura 2a-b). O material coletado foi utilizado para análises visuais, anatômicas e micromorfométricas.

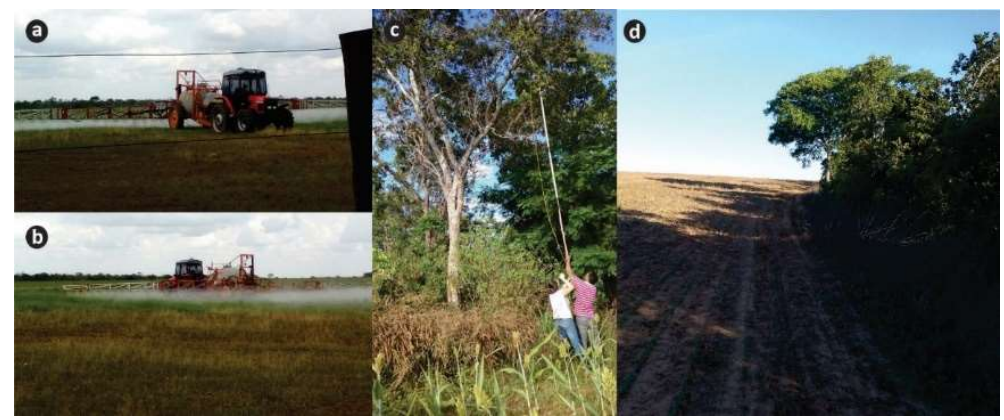

Figura 2: a) Veículo equipado com o pulverizador Columbria 3000 sprayer, jato cônico vazio com 14 bicos; b) Pulverização e ação do vento; c) Coleta de folhas na AB com uso de podão; d) área de manejo com solo descoberto e borda de remanescente nativos na AB. Fotos: a e b (Paggiaro, 2018); c e d (Autora).

\section{Avaliação visual de sintomas foliares}

Cinco folhas de cada indivíduo foram escolhidas, aleatoriamente, para estimar a porcentagem de área foliar ocupada por injúrias, para cada área de estudo, nas duas coletas. Dessa forma as folhas foram classificadas como: $0\left(\mathrm{~N}_{0}\right),<5 \%\left(\mathrm{~N}_{1}\right), 5$ a $25 \%\left(\mathrm{~N}_{2}\right), 25 \%$ a $50 \%\left(\mathrm{~N}_{3}\right), 50 \%$ a $75 \%\left(\mathrm{~N}_{4}\right)$ e $76 \%$ a $100 \%\left(\mathrm{~N}_{5}\right) . \mathrm{N}_{0}$ é a classe correspondente à ausência de injúria e $\mathrm{N}_{1}$ a $\mathrm{N}_{5}$ correspondem às lesões de primeiro ao quinto grau da área foliar. A avaliação das lesões ocorreu por estimativa visual e o índice de injúria foliar (IIF) foi calculado usando a equação de Chang et al. (2001):

Índice de Injúria Foliar $(\mathrm{IIF} \%)=\frac{(\mathrm{N} 1 * 1)+(\mathrm{N} 2 * 2)+(\mathrm{N} 3 * 3)+(\mathrm{N} 4 * 4)+(\mathrm{N} 5 * 5)}{(\mathrm{N} 0+\mathrm{N} 1+\mathrm{N} 2+\mathrm{N} 3+\mathrm{N} 4+\mathrm{N} 5) * 5} * 100$

No dividendo as classes ( $\mathrm{Nx}$ ) foram multiplicadas pelo peso da lesão foliar. No divisor o número de folhas enquadradas em cada classe foi somado e multiplicado pelo número das classes de sintomas (cinco). 
Também foi realizado cálculo para determinar o índice de severidade (IS) para os sintomas visíveis nas folhas, por área e em cada coleta. O número de folhas com sintomas foi dividido pelo número total de folhas por planta, expresso na seguinte equação:

$$
\text { Índice de Severidade }(\mathrm{IS} \%)=\frac{\text { Número de folhas com sintomas }}{\text { Total de folhas }} * 100
$$

IIF representa a porcentagem de área foliar ocupada por injúrias e o IS a porcentagem de folhas com sintomas foliares, em relação ao número total de folhas verificadas. Ambos os índices foram aplicados a todos os tipos de injúrias observadas nas folhas, uma vez que o herbicida glifosato pode favorecer a ação de doenças foliares, através de sua interferência na formação de barreiras mecânicas e produção de defesas vegetais (YAMADA et al., 2007). Ou seja, não só causa danos às plantas, mas também torna suas folhas suscetíveis a doenças.

\section{Análises anatômicas}

Amostras da região mediana de cinco folhas foram coletadas e fixadas em solução karnovsky (KARNOVSKY, 1965) por 24 horas, desidratadas em série etílica crescente até o álcool 70\%, onde ficaram armazenadas. Posteriormente foram desidratadas em 1 hora, para cada troca em séries etílicas e butílicas, permanecendo em 'over night' em ácool butílico e parafina (1:1), e depois submetidas a duas trocas de parafina por 1 hora cada.

As amostras foram emblocadas seguindo a orientação do plano de corte transversal e o micrótomo

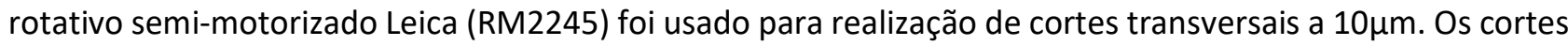
foram aderidos à lâmina por adesivo de Haupt (HAUPT, 1930) e cinco lâminas foram confeccionadas para cada indivíduo, por área, e para cada coleta.

Os cortes foram desparafinizados em série xilóica, hidratados em série etílica e corados em safranina 1\% e azul de astra por 20 minutos (GERLACH, 1984). Em seguida foram lavados em água destilada, desidratados em série etílica e submetidos à série xilóica. As lâminas foram montadas entre lâmina e lamínula com bálsamo canadense. As imagens foram capturadas com uso de microscópio óptico Leica DM 500, com uma câmera Leica ICC50 HD acoplada.

\section{Análises micromorfométricos}

Aleatoriamente foi escolhido um corte de cada uma das cinco lâminas, de cada indivíduo, por cada área e em cada coleta para esta análise. A captura das imagens ocorreu como descrito no item 'análises anatômicas'. As medidas micromorfométricas foram feitas com o uso do software Anati Quanti, versão 2.0 para Windows ${ }^{\circledR}$ (AGUIAR et al., 2007). Em cada corte foram realizadas dez medidas, em locais distintos, da espessura dos tecidos da epiderme (nas faces adaxial e abaxial), do parênquima paliçádico e da hipoderme. Os dados foram submetidos à análise de variância e teste de Tukey a $5 \%$ de probabilidade pelo software estatístico R. 


\section{RESULTADOS}

\section{Avaliação visual de sintomas foliares}

Cloroses, enrugamento e necroses, em diferentes formatos, foram observados nas folhas de $B$. virgilioides (Figuras 3a-d).
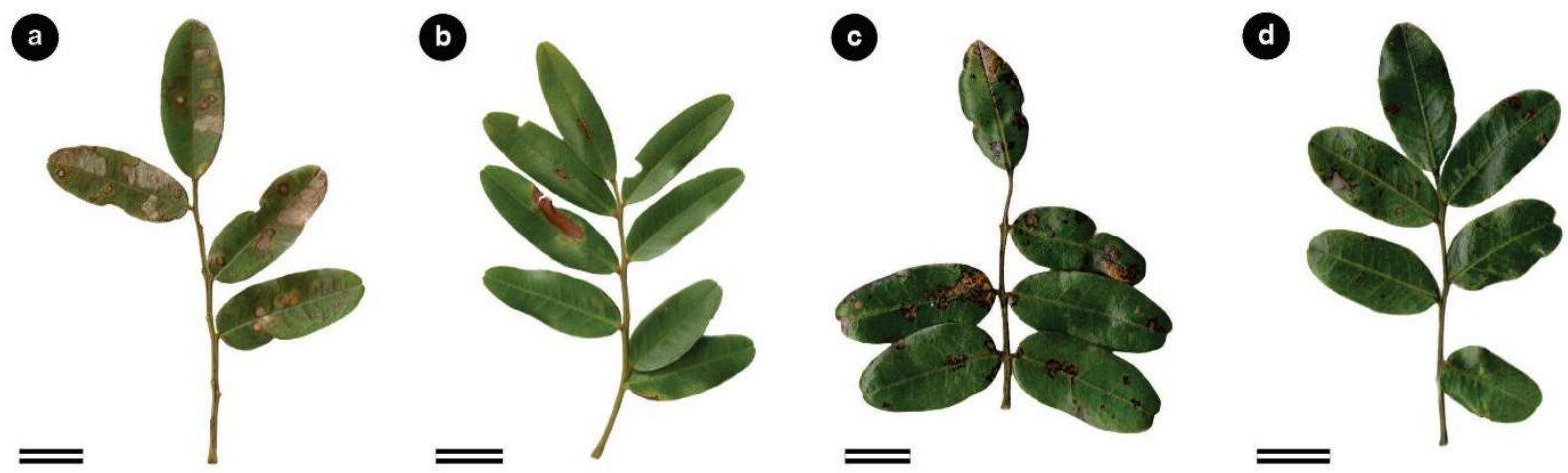

Figura 3: Cloroses, necroses e enrugamento nas folhas de a) $A B$ em novembro de 2016; b) AC em novembro de 2016; c) $A B$ em maio de 2017; d) $A C$ em maio de 2017. Barra $=2 \mathrm{~cm}$.

Os percentuais dos índices de injúria foliar e de severidade para a $A B$ foram maiores que os da $A C$, conforme tabela 1. Entre coletas, os maiores percentuais ocorreram na segunda, realizada em maio de 2017.

Tabela 1: Percentuais dos índices de injúria foliar e de severidade das folhas de $B$. virgilioides por área de estudo e por coleta.

\begin{tabular}{lllll}
\hline \multirow{2}{*}{ Coletas } & AC & & AB & \\
\cline { 2 - 5 } & IIF (\%) & IS (\%) & IIF (\%) & IS (\%) \\
\hline Novembro/2016 & 15.2 & 76 & 17.2 & 80 \\
Maio/2017 & 19.2 & 88 & 25.6 & 90 \\
\hline AC: Area Contro
\end{tabular}

AC: Área Controle; AB: Área de Borda; IIF: Índice de Injúria Foliar e IS: Índice de Severidade.

\section{Análises anatômicas}

A epiderme das folhas de $B$. virgilioides é unisseriada em ambas as faces (adaxial e abaxial), com a presença de microcristais nos vacúolos, sendo suas células da epiderme adaxial maiores (Figura 4a). A cutícula é espessa e seus estômatos estão presentes na face abaxial da epiderme, classificando as folhas como hipoestomáticas (Figura 4d). O mesofilo possui camadas bem definidas de parênquima paliçádico e, na região do parênquima lacunoso, observou-se uma hipoderme bem marcada voltada para face abaxial (Figuras 4a-d). Também possui fibras pericíclicas e gelatinosas na bainha dos feixes vasculares em suas nervuras (Figura 4c).

Alterações anatômicas foram observadas nos tecidos das folhas das plantas em ambas as áreas. No entanto, os sintomas nas folhas da AB foram mais expressivos. Foram encontradas alterações nos formatos dos cloroplastos, que apresentaram formas arredondadas (Figura 4a), diferentemente do seu formato natural que é elipsóide.

Outros sintomas encontrados foram plasmólise celular (Figura 4d), hiperplasia (Figura 4b), proliferação celular, principalmente no parênquima paliçádico (Figura 4c), formação de tecido de cicatrização e colapso celular com necrose (Figura 4e). Foi observada uma camada de células bem desenvolvidas, no local onde era previsto a ocorrência do parênquima lacunoso, e denominadas aqui de hipoderme. Também houve 
presença e acúmulo de substâncias, de coloração vermelho escuro, que aparentavam compostos fenólicos, entretanto testes histoquímicos não foram realizados para confirmação. Essas substâncias estavam presentes no parênquima paliçádico, na hipoderme e nas células do entorno à nervura principal (Figuras 4a, $b, d, e, f)$. Na segunda coleta foi observada a presença de fungos na epiderme das folhas coletadas nas duas áreas, sendo que na AC esses organismos estavam dentro dos estômatos da epiderme abaxial (Figura 4f).

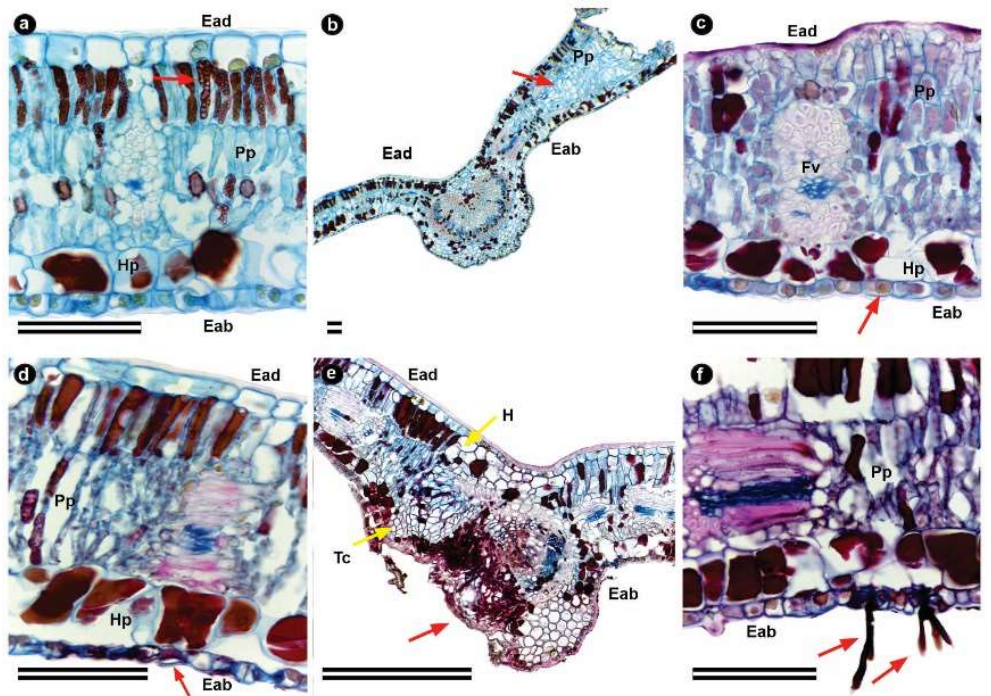

Figura 4: Cortes transversais de folhas de $B$. virgillioides oriundas da $A B(a, b, d, e)$ e $A C$ (c, f). a) Alterações nos cloroplastos, com formatos arredondados, indicado por seta; b) hiperplasia, indicada por seta; c) tecido de cicatrização na extensão do parênquima paliçádico e presença de cristais, indicado por seta; d) plasmólise celular evidenciada por seta; e) hiperplasia e tecido de cicatrização, apontados por seta amarela, e colapso celular (necrose) na nervura principal, indicado por seta vermelha; f) detalhe de fungos dentro dos estômatos. Ead: epiderme adaxial;

Eab: epiderme abaxial; Hp: hipoderme; Pp parênquima paliçádico; Fv: feixe vascular; H: hiperplasia; Tc: tecido de cicatrização. Barra: $100 \mu \mathrm{m}$.

\section{Análises micromorfométricas}

Tanto a hipoderme (Hp), quanto às faces adaxial (Ead) e abaxial (Eab) da epiderme, não diferiram na espessura, entre áreas e coletas (Tabela 2). No entanto, as espessuras do parênquima paliçádico (Pp) e mesofilo (limbo foliar- Lf) da AB diferiram significativamente entre coletas, assim como entre os indivíduos da AC e da AB na coleta de maio de 2017.

Tabela 2: Morfometria de folhas de Bowdichia virgilioides comparada entre áreas e coletas pelo teste de Tukey a 5\% de probabilidade.

\begin{tabular}{lllllll}
\hline Coletas & Áreas & Ead $(\mu \mathrm{m})$ & Pp $(\mu \mathrm{m})$ & $\mathbf{H p}(\mu \mathrm{m})$ & Eab $(\mu \mathrm{m})$ & Lf $(\mu \mathrm{m})$ \\
\hline \multirow{2}{*}{ Novembro/2016 } & AC & 21.24 a A & 130.73 a A & 40.77 a A & 16.29 a A & 209.04 a A \\
& AB & 22.32 a A & 137.74 a A & 39.98 a A & 15.56 a A & 215.62 a A \\
\hline \multirow{2}{*}{ Maio/2017 } & AC & 22.86 a A & 131.69 a A & 40.26 a A & 15.95 a A & 210.77 a A \\
& AB & 23.52 a A & 152.03 b B & 41.24 a A & 14.99 a A & 231.79 b B \\
\hline
\end{tabular}

Ead: epiderme adaxial; Pp: parênquima paliçádico; Hp: hipoderme; Eab: epiderme abaxial; Lf: limbo foliar. Letras minúsculas: comparação entre áreas. Letras maiúsculas: comparação entre coletas na mesma área.

\section{DISCUSSÃO}

\section{Avaliação visual de sintomas foliares}

De acordo com Machado et al. (2013), quando submetidas a baixas concentrações do herbicida glifosato, as espécies Plathymenia reticulata Benth, B. virgilioides, K. lathrophyton e S. lycocarpum 
apresentaram sintomas visuais de intoxicação, sendo cloroses e necroses os sintomas mais evidentes. Silva et al. (2019) também verificaram sintomas visuais para Pouteria torta Mart. (Sapotaceae), Silva et al. (2020) para Handroanthus chrysotrichus Mart. Ex DC (Bignoniaceae) e Santos et al. (2020) para C. macrophyllum. Mudanças na coloração podem estar relacionadas às alterações nos cloroplastos (CRUZ et al., 2021; CAMPBEL et al., 1976) ou na inibição da formação de clorofila (COLE et al., 1983). Ainda não existe chave de identificação para cloroses e necroses ocasionadas por agrotóxicos, como as chaves utilizadas para ozônio (INNES et al., 2001), por isso algumas necroses observadas (Figuras 4a-d) também podem ser doenças.

Os percentuais de IIFs são baixos, cerca de $5 \%$ a $25 \%$ de lesões nas folhas. Entretanto, o percentual de folhas com alguma injúria (ISs), independentemente do tamanho, é relativamente alto. Os maiores percentuais de IIFs e ISs nas folhas das plantas da AB eram esperados por esta área ser localizada na borda de manejo agrícola e, consequentemente, ser suscetível a sofrer impactos diversos e diretos advindos da lavoura, como a deriva de herbicidas. Em estudo sobre simulação de deriva de glifosato, em B. virgilioides, foi percebido que os IIFs variaram de $10,8 \%$ a $37,7 \%$, e os ISs de $36 \%$ a $75 \%$, da menor a maior dose, e que o herbicida teve ação lenta e de baixa intensidade nas folhas quando comparado ao herbicida paraquat, porém, 168h após aplicação foram potencializados (OLIVEIRA, 2014). Os percentuais de IIFs encontrados para as duas áreas desta pesquisa estão entre o intervalo apresentado por Oliveira (2014) e os ISs foram maiores, provavelmente por que em campo as plantas estão mais suscetíveis às diversas fontes causadoras de injúrias.

A avaliação visual dos sintomas foliares em pesquisas a nível de campo não deve ser utilizada isoladamente, visto que existe possibilidade de que a necrose não seja proveniente da ação direta do herbicida, mas de outras causas como as doenças. Contudo, o surgimento de doenças não exclui a ação indireta do glifosato, pois este herbicida tende a inibir a produção de lignina e fitoalexinas em níveis adequados e por isso compromete a barreira de defesa das plantas, tornando-as suscetíveis à ação de doenças (YAMADA et al., 2007). Adicionalmente, também causa impactos nos parâmetros fotossintéticos, em consequência da inibição/diminuição da ação da enzima 5 enolpiruvil-chiquimato-3-fosfato-sintase (EPSPS) e, consequentemente, pelo acúmulo da rota metabólica do ácido chiquímico nos tecidos das plantas, o que afeta o desenvolvimento e suas defesas, tendo em vista que reduz a síntese de aminoácidos aromáticos essenciais, como a fenilalanina, tirosina e triptofano (GOMES et al., 2017; SILVA et al., 2020; SANTOS et al., 2020).

\section{Análises anatômicas}

A maioria dos cortes histológicos foram realizados em regiões aparentemente sadias. Mas, anatomicamente as folhas apresentaram sintomas similares aos das plantas de $B$. virgilioides expostas ao glifosato em ambiente controlado (OLIVEIRA et al., 2021). As alterações ultraestruturais precedem o aparecimento dos sintomas visuais (SANTOS et al., 2008), por isso os sintomas anatômicos apresentados na figura 4 precedem as lesões foliares da figura 3, exatamente por serem microscópicas e, às vezes, ocorrerem lentamente, o que enfatiza a importância de estudos morfoanatômicos.

As alterações no formato dos cloroplastos podem estar relacionadas com o processo de senescência 
foliar, que tende a ser estimulado e aumentado pelo glifosato (CAMPBEL et al., 1976). Conforme esses autores, na visualização de efeitos do glifosato em gramíneas, quando a folha está em processo de senescência, ocorre perda de clorofila e também de grande proporção de proteína. Como parte expressiva das proteínas de folhas verdes ficam nos cloroplastos, não há como perdê-las sem que essa organela seja prejudicada. Em plantas arbóreas de Eugenia uniflora L. (Myrtaceae), após exposição ao glifosato, também foram observadas alterações nos cloroplastos e foram atribuídas ao acúmulo de amido nestas organelas em função da provável interferência do glifosato na ação do floema, tecido responsável por transportar estas substâncias na planta (CRUZ et al., 2021).

Mudanças nas estruturas anatômicas das folhas, como tecido de cicatrização, demonstram que as plantas investiram na produção de barreiras no intuito de salvarem seus tecidos sadios, mas, as células das folhas deste estudo foram destruídas, como observado na Figura 4e., e alguns estudos mostram que o glifosato pode ocasionar o colapso celular das folhas das plantas. Os sintomas de plasmólise celular, hiperplasia, proliferação celular, formação de tecido de cicatrização e colapso celular com necrose, também foram encontrados por Santos et al. (2008) em folhas de Eucalyptus grandis W. Hill ex Maiden clones, e por Silva et al. (2016) em folhas de C. brasiliense, expostas à simulação de deriva de glifosato em ambiente controlado. Silva et al. (2020) encontraram necroses e rupturas das células do mesofilo em H. chrysotricus, Oliveira et al. (2021) verificaram tecido de cicatrização e plasmólise celular em folhas de B. virgilioides, e Cruz et al. (2021) plasmólise e colapso celular em E. uniflora, todas expostas ao glifosato.

Neste estudo, a hipoderme bem marcada na região onde localiza-se o parênquima lacunoso de $B$. virgilioides chamou atenção por sua presença ser uma característica peculiar. Esta hipoderme pode estar comportando-se também como uma barreira protetora, em função da exposição por deriva do glifosato, uma vez que são células justapostas, com poucos espaços celulares (Figura 4), diferente do tradicional parênquima lacunoso, que é um tecido com muitos espaços celulares. Este tecido não foi observado em plantas sob condições controladas de exposição ao glifosato (Oliveira et al., 2021; MACHADO et al., 2013) e, sua presença, não é característica da anatomia convencional destas plantas.

O acúmulo de substâncias, evidenciadas pela cor vermelho escuro, foi observado nos tecidos das folhas (figura 4) e acredita-se que sejam compostos fenólicos, porém não foi realizado teste histoquímico para confirmação. Oliveira et al. (2021) não encontraram compostos fenólicos nos tecidos das folhas desta espécie para indivíduos controle (sem exposição ao glifosato). No entanto, quando submetidas às doses desse herbicida, compostos fenólicos, confirmados por testes histoquímicos, apareciam e aumentavam sua ocorrência nas células. Esses compostos tendem a estar presentes nas interações de plantas com fatores abióticos, inclusive fatores artificiais, como poluentes, podem interferir nesse processo e influenciar sua produção (DICKISON, 2000; CRUZ et al., 2021). Diante disso, a realização de testes histoquímicos para verificar se essas substâncias são compostos fenólicos é necessária e, se forem confirmados, podem ser respostas das plantas às condições de estresse.

Os fungos encontrados na face abaxial da epiderme da AC, das folhas oriundas da segunda coleta, evidenciam o comprometimento das barreiras de defesa dessas plantas, como demonstrado anteriormente 
no item de 'avaliação visual de sintomas foliares'. Até a realização da segunda coleta outras prováveis pulverizações ocorreram na lavoura, e associadas com maior período de exposição e ação do contaminante, assim como com o período chuvoso e aumento da umidade do ar na região, pode ter influenciado a ação e desenvolvimento desses organismos sobre as folhas dessas plantas.

\section{Análises micromorfométricas}

Alguns fatores podem explicar a diferença significativa da espessura do parênquima paliçádico ( $\mathrm{Pp})$ da $A B$ entre coletas, assim como para a $A C$ na segunda coleta. As plantas da área de borda são mais suscetíveis à incidência solar e por isso, ao processo do desenvolvimento e diferenciação entre folhas de sombra e de sol. Segundo Taiz et al. (2004) as folhas que estão sob maior incidência solar, geralmente, tendem a ser mais espessas e as folhas de áreas sombreadas mais finas. Além disso, as plantas de borda tendem a sofrer impactos diversos e diretos da área de entorno. A segunda coleta ocorreu em maio de 2017, período em que as plantas ainda não haviam trocado suas folhas (geralmente por volta de junho) e, portanto, ficaram expostas a outras pulverizações, assim como expostas a ação do contaminante por maior período de tempo, o que pode ter potencializado o efeito do herbicida nas células do Pp. Neste tecido foram observados alongamento da parede celular anticlinal, aumento no número de camadas celulares e, em alguns cortes, um maior grau de diferenciação e multiplicação celular (Figura 4) e, consequentemente, suas alterações provocaram as alterações nas espessuras do Lf. Conforme Pereira et al. (2015), a sensibilidade ao glifosato varia de acordo com a espécie e dose usada, ora estimulando o crescimento, ora causando injúrias e morte da planta. O estímulo das plantas ao crescimento por baixas doses de substâncias consideradas tóxicas é denominado hormese (SILVA et al., 2016), o que provavelmente ocorreu com o Pp da AB na segunda coleta.

Em relação à epiderme abaxial, nos trabalhos de Oliveira et al. (2021) e Machado et al. (2013), realizados com $B$. virgilioides expostas ao glifosato em ambiente controlado, ocorreu a redução da espessura desse tecido, diferente deste estudo desenvolvido em campo, e pode ser por que não tenha ocorrido deriva suficiente para causar alterações na espessura da Eab. Embora não tenha existido diferença para a hipoderme, não foi possível compará-la com trabalhos realizados em ambiente controlado pois os indivíduos deste estudo apresentaram hipoderme ao invés de parênquima lacunoso.

\section{CONCLUSÕES}

As folhas coletadas apresentaram baixo percentual de área foliar ocupada por injúrias, em ambas as áreas e coletas, mas os índices de severidade indicaram que as suas maiorias apresentaram algum nível de injúria. Sintomas semelhantes aos de deriva de glifosato foram constatados: hiperplasia, plasmólise celular, colapso celular, tecido de cicatrização e hormese. O único tecido com diferença na espessura foi o Pp da área de borda na segunda coleta, indicando influência do efeito hormese. A presença de hipoderme, no local do parênquima lacunoso sugere barreira protetiva destas plantas na via de entrada do glifosato. Nesta pesquisa de campo, as avaliações visuais, anatômicas e morfométricas sugeriram deriva do herbicida em ambas as áreas de estudo. 
Este estudo pode auxiliar no delineamento de futuros trabalhos sobre deriva de agrotóxicos em campo e com uso de espécies nativas do Cerrado, avaliadas em ambiente controlado como bioindicadoras. É sugerido a realização de monitoramento que observe maior período de tempo e os ciclos foliares das plantas, tendo em vista que folhas jovens podem apresentar diferentes alterações naturais. Análises químicas de herbicidas nas folhas, e em períodos semelhantes aos estudados, também são sugeridas para validação das análises morfoanatômicas usadas em trabalhos como este.

AGRADECIMENTOS: Ao Conselho Nacional de Desenvolvimento Científico e Tecnológico - CNPQ pela bolsa de mestrado (no 133632/2016-4) concedida à primeira autora. À família Paggiaro pela disponibilização das áreas de estudo para desenvolvimento da pesquisa. À Juliana, Victorina, Hiron, e sua família, pelo auxílio em campo.

\section{REFERÊNCIAS}

AGUIAR, T. V.; SANT'ANNA-SANTOS, B. F.; AZEVEDO, A. A.; FERREIRA, R. S.. Anati Quanti: Quantitative analysis software for plant anatomy studies. Planta Daninha, v.25, n.4, p.649659, 2007. DOI: http://doi.org/http://dx.doi.org/10.1590/S0100$\underline{83582007000400001}$

ALBUQUERQUE, K. S.; GUIMARÃES, R. M.; ALMEIDA, Í. F.; CLEMENTE, A. C. S.. Métodos para a superação da dormência em semente de sucupira-preta (Bowdichia virgilioides KUNTH.). Ciência e Agrotecnologia, v.31, n.6, p.1716-1721, 2007. DOI: http://doi.org/10.1590/S141370542007000600017

BRASIL. Lei n.12.651, de maio de 2012. Dispõe sobre a proteção da vegetação nativa; altera as Leis nos 6.938, de 31 de agosto de 1981, 9.393, de 19 de dezembro de 1996, e 11.428 , de 22 de dezembro de 2006; revoga as Leis nos 4.771, de 15 de setembro de 1965, e 7.754, de 14 de abril de 1989, e a Medida Provisória no 2.166-67, de 24 de agosto de 2001; e dá outras providências. Brasília: DOU, 2012.

BUENO, M. R.; CUNHA, A. R.; SANTANA, D. G.. Assessment of spray drift from pesticide applications in soybean crops. Biosystems Engineering, v.4, n.54, p.35-45, 2017. DOI: http://doi.org/10.1016/j.biosystemseng.2016.10.017

CAMPBEL, W. F.; EVANS, J. O.; REED, S. C.. Effects of gliphosate on chloroplast ultrastucture of quacgrass mesophyll cells. Weed Science, v.24, n.1, p.22-25, 1976. DOI: http://doi.org/10.1614/WS-D-09-00083

CHANG, Y. S.; YU, M. R.. Correlation between ozone resistance and relative clorophyll fluorescence or relative stomatal conductance of bedding plants. Botanical Bulletin of Academic Sinica, v.42, p.265-272, 2001.

COLE, D. J.; CASELEY, J. C.; DODGE, A. D.. Influence of glyphosate on selected plant processes. Weed Research, v.23, n.3, p.173-183, 1983. DOI: http://doi.org/10.1111/j.1365-3180.1983.tb00535.x

Cruz, C. E. S.; FREITAS-SILVA, L.; RIBEIRO, C.; SILVA, L. C.. Physiological and morphoanatomical effects of glyphosate in
Eugenia uniflora, a Brazilian plant species native to the Atlantic Forest biome Environmental. Science and Pollution Research, v.28, p.21334-21346, 2021. DOI: http://doi.org/10.1007/s11356-020-12003-4

CUNHA, P. J. R. A.. Simulação da deriva de agrotóxicos em diferentes condições de pulverização. Ciência e Agrotecnologia, v.32, n.5, p.1616-1621, 2008. DOI: http://doi.org/http://dx.doi.org/10.1590/S141370542008000500039

DICKISON, W. C.. Integrative Plant Anatomy. Elsevier, 2000.

EGAN, J. F.; BOHNENBLUST, E.; GOSLEE, S.; MORTENSEN, D.; TOOKER, J.. Herbicide drift can affect plant and arthropod communities. Agriculture, Ecosystems and Environment, v.185, p.77-87, 2014. DOI:

http://dx.doi.org/10.1016/j.agee.2013.12.017

GALLI, A. J. B.; MONTEZUMA, M. C.. Alguns aspectos da utilização do herbicida glifosato na agricultura. ACADCOM Ltda, 2005.

GEIGER, F.; BENGTSSON, J.; BERENDSE, F.; WEISSER, W. W.; EMMERSON, M.; MORALES, M. B.; CERYNGIER, P.; LIIRA, J.; TSCHARNTKE, T.; WINQVIST, C.; EGGERS, S.; BOMMARCO, R.; PÄRT, T.; BRETAGNOLLE, V.; PLANTEGENEST, M.; CLEMENT, L. W.; DENNIS, C.; PALMER, C.; ONÃTE, J. J.; INCHAUSTI, P.. Persistent negative effects of pesticides on biodiversity and biological control potential on European farmland. Basic and Applied Ecology, v.11, p.97-105, 2010. DOI: http://doi.org/10.1016/i.baae.2009.12.001

GERLACH, D.. Botanische Mikrotechnik: Eine Einführung. Sttutgart: Georg Thieme Verlag, 1984.

GOMES, M. P.; MANAC'H, L.; SARAH, G.; HÉNAULT-ETHIER, L.; LABRECQUE, M.; LUCOTTE, M.. Glyphosate-dependent inhibition of photosynthesis in willow. Frontiers in Plant Science, v.8, p.207, 2017. DOI:

http://doi.org/10.3389/fpls.2017.00207

HAUPT, A. W.. A Gelatin Fixative for Paraffin Sections. Stain Tchnology, v.5, n.3, p.97-98, 1930. 
IBAMA. Instituto Brasileiro do Meio Ambiente e dos Recursos Naturais Renováveis. Os 10 ingredientes ativos mais vendidos - 2019. IBAMA, 2020.

INMET. Instituto Nacional de Meteorologia. Estação Rio Sono A050: novembro de 2016. Banco de Dados Meteorológicos do INMET, 2016.

INMET. Instituto Nacional de Meteorologia. Estação Rio Sono A050: maio de 2017. Banco de Dados Meteorológicos do INMET, 2017.

INNES, J. L.; SKELLY, J. M.; SCHAUB, M.. Ozone and broadleaved species. A guide to the identification of ozoneinduced foliar injury. Ozon, Laubholz- und Krautpflanzen. Ein Führer zum Bestimmen von Ozonsymptomen. Birmensdorf, Eidgenössische Forschungsanstalt WSL. Bern, Stuttgart, Wien; Haupt, 2001.

INPE. Instituto Nacional de Pesquisas Espaciais. TOPODATA: Banco de dados geomorfométricos do Brasil. INPE, 2008.

KARNOVSKY, M. J.. A formaldehyde glutaraldehyde fixative of high osmolality for use in electron microscopy. Journal of Cell Biology, v.27, p.137-138, 1965.

LUCADAMO, L.; CORAPI, A.; GALLO, L.. Evaluation of glyphosate drift and anthropogenic atmospheric trace elements contamination by means of lichen transplants in a southern Italian agricultural district. Air Quality, Atmosphere \& Health, v.11, p.325-339, 2018. DOI: http://doi.org/10.1007/s11869-018-0547-7

MACHADO, V. M.; SANTOS, J. B.; PEREIRA, I. M.; LARA, R. O.; CABRAL, C. M.; AMARAL, C. S.. Sensibilidade de mudas de espécies florestais nativas ao glyphosate. Bioscience Journal, v.29, n.6, p.1941-1951, 2013.

MAPBIOMAS. Coleção [4.1] da Série Anual de Mapas de Cobertura e Uso de Solo do Brasil. MAPBIOMAS, 2018.

MYERS, N.; MITTERMEIER, R. A.; MITTERMEIER, C. G.; FONSECA, G. A. B.; KENT, J.. Biodiversity hotspots for conservation priorities. Nature, v.403, p.853-858, 2000. DOI: http://doi.org/10.1038/35002501

OLIVEIRA, A. P.. Respostas fisiológicas e morfoanatômicas de Bowdichia virgilioides KUNTH. (FABACEAE) exposta a herbicidas. Dissertação (Mestrado em Ecologia de Ecótonos) - Universidade Federal do Tocantins, Porto Nacional, 2014.

OLIVEIRA, A. P.; CRISPIM FILHO, A. J.; COSTA, A. C.; SILVA, K. L. F.. Respostas fisiológicas e morfoanatômicas de Bowdichia virgilioides KUNTH. (FABACEAE) ao glifosato. Revista Árvore, v.45, 2021. DOI: http://doi.org/10.1590/1806-908820210000028

PEREIRA, M. R. R.; SOUZA, G. S. F.; FONSECA, E. D.; MARTINS, D.. Subdoses de glyphosate no desenvolvimento de espécies arbóreas nativas. Bioscience Journal, v.31, n.2, p.326-332, 2015.

PIRANI, F. R.; SANCHEZ, M.; PEDRONI, F.. Phenology of a tree community in a cerrado sensu stricto, Barra do Garças, Mato Grosso state, Brasil. Acta Botanica Brasilica, v.23, n.4, p.1096-1109, 2009. DOI: http://dx.doi.org/10.1590/\$0102-
33062009000400019

RAUSCH, L. L.; GIBBS, H. K.; SCHELLY, I.; BRANDÃO JUNIOR, A.; MORTON, D. C.; FILHO, A. C.; STRASSBURG, B.; WALKER, N.; NOOJIPADY, P.; BARRETO, P.; MEYER, D.. Soy expansion in Brazil's Cerrado. Conservation Letters, p.1-10, 2019. DOI: http://doi.org/10.1111/conl.12671

REDDY, K. N.; DING, W.; ZABLOTOWICZ, R. M.; THOMSON, S. J.; HUANG, Y.; KRUTZ, L. J.. Biological responses to glyphosate drift from aerial application in non-glyphosateresistant corn. Pest Management Science, v.66, n.10, p.1148-1154, 2010. DOI: http://doi.org/10.1002/ps.1996

SANTOS, L. D. T.; SANT'ANNA-SANTOS, B. F.; MEIRA, R. M. S A.; TIBURCIO, R. A. S.; FERREIRA, F. A.; MELO, C. A. D.; SILVA, E. F. S.. Danos visuais e anatômicos causados pelo glyphosate em folhas de Eucalyptus grandis. Planta Daninha, v.26, n.1, p.9-16, 2008. DOI: http://doi.org/10.1590/S010083582008000100002

SANTOS, V. R. S.; CRISPIM FILHO, A. J.; SANTANA, M. M.; COSTA, A. C.; SILVA, K. L. F.. Análises fisiológicas e morfoanatômicas de Cenostigma macrophyllum Tul. (Fabaceae) submetida a diferentes concentrações de glifosato. Revista Ibero-Americana de Ciências Ambientais, v.11, n.5, p.159-173, 2020. DOI: http://doi.org/10.6008/cbpc2179-6858.2020.005.0017

SCHRÜBBERS, L. C.; VALVERDE, B. E.; SØRENSEN, J. C.; CEDERGREEN, N.. Glyphosate spray drift in Coffea arabica Sensitivity of coffee plants and possible use of shikimic acid as a biomarker for glyphosate exposure. Pesticide Biochemistry and Physiology, v.115, p.15-22, 2014. DOI: http://doi.org/10.1016/j.pestbp.2014.08.003

SILVA, J. M. C.; BATES, J. M.. Biogeographic Patterns and Conservation in the South American Cerrado: A Tropical Savanna Hotspot. Bio Science, v.52, n.3, p.225-233, 2002. DOI: http://doi.org/10.1641/00063568(2002)052[0225:BPACIT]2.0.CO;2

SILVA, L. Q.; JAKELAITIS, A.; VASCONCELOS FILHO, S. C.; COSTA, A. C.; ARAÚJO, A. C. F.. Morpho-anatomical changes of pequi leaves (Caryocar brasiliense Cambess.) exposed to simulated drift of glyphosate. Revista Árvore, v.40, p.669677, 2016. DOI: http://doi.org/10.1590/0100$\underline{67622016000400010}$

SILVA, L.; ARAÚJO, T. O.; NUNES-NESI, A.; RIBEIRO, C.; COSTA, A. C.; SILVA, L. C.. Evaluation of morphological and metabolic responses to glyphosate exposure in two neotropical plant species. Ecological Indicators, v.113, p.106246, 2020. DOI:

http://doi.org/10.1016/j.ecolind.2020.106246

SILVA, S. L.; CARLOS, A.; HENRIQUE, F.; FERREIRA, P.; CRISPIM FILHO, A. J.; JULIANE, K.; NASCIMENTO, T.; ALVES, A.. Pouteria torta is a remarkable native plant for biomonitoring the glyphosate e ff ects on Cerrado vegetation. Ecological Indicators, v.102, p.497-506, 2019. DOI: http://doi.org/10.1016/j.ecolind.2019.03.003

SOUZA, L. A.; CUNHA, J. P. A. R.; PAVANIN, L. A.. Eficácia e perda do herbicida 2,4-D amina aplicado com diferentes volumes de calda e pontas de pulverização. Planta Daninha, v.29, p.1149-1156, 2011. DOI: 
http://doi.org/10.1590/S0100-83582011000500023

SOUZA, L. B.; CHAVEIRO, E. F.. Território, ambiente e modos de vida: conflitos entre o agronegócio e a Comunidade Quilombola de Morro de São João, Tocantins. Sociedade e Natureza, v.31, p.1-26, 2018. DOI:

http://dx.doi.org/10.14393/SN-v31n1-2019-42482

SPERA, S. A.; GALFORD, G. L.; COE, M. T.; MACEDO, M. N.; MUSTARD, J. F.. Land-use change affects water recycling in Brazil's last agricultural frontier. Global change biology, v.22, n.10, p.3405-3413, 2016. DOI: http://doi.org/10.1111/gcb.13298

TAIZ, L.; ZEIGER, E.. Fisiologia e desenvolvimento vegetal. Porto Alegre: Artmed, 2004.
TEMMERMAN, L.; BELL, N. B.; GARREC, J. P.; KLUMPP, A.; KRAUSE, G. H. M.; TONNEIJCK, A. E. G.. Biomonitoring of air pollutants with plants: considerations for the future. In: KLUMPP, A.; ANSEL. W.; KLUMPP, G.. Urban air pollution, bioindication and environmental awareness. Göttingen: Cuvillier Verlag, 2004. p.393.

YAMADA, T.; CASTRO, P. R. D. C. E.. Efeitos do glifosato nas plantas: implicações fisiológicas e agronômicas. Informações Agronômicas, n.19, p.1-32, 2007.

ZHANG, X.; LUO, Y.; GOH, K. S.. Modeling spray drift and runoff-related inputs of pesticides to receiving water. Environmental Pollution, v.234, p.48-58, 2018. DOI: http://doi.org/10.1016/i.envpol.2017.11.032

A CBPC - Companhia Brasileira de Produção Científica (CNPJ: 11.221.422/0001-03) detém os direitos materiais desta publicação. Os direitos referem-se à publicação do trabalho em qualquer parte do mundo, incluindo os direitos às renovaç̃ões, expansões e disseminações da contribuição, bem como outros direitos subsidiários. Todos os trabalhos publicados eletronicamente poderão posteriormente ser publicados em coletâneas impressas sob coordenação da Sustenere Publishing, da Companhia Brasileira de Produção Científica e seus parceiros autorizados. Os (as) autores (as) preservam os direitos autorais, mas não têm permissão para a publicação da contribuição em outro meio, impresso ou digital, em português ou em tradução. 